International Journal of Biology, Pharmacy and Allied Sciences (IJBPAS) 'A Bridge Betusen Caboratory and QRader'

Www.ijbas.com

\title{
A CASE OF PSEUDOMYOPIA
}

\section{HASHMA MOHAMMED}

Post Graduate, Department of Paediatrics, Sree Balaji Medical College and Hospital, Chrompet, Chennai-600044

"Corresponding Author: Dr. Hashma Mohammed: Email: hashmamp95@gmail.com

Received 25 ${ }^{\text {th }}$ March. 2021; Revised 26 ${ }^{\text {th }}$ April 2021; Accepted 22 ${ }^{\text {nd }}$ May 2021; Available online $1^{\text {st }}$ Dec. 2021

\section{https://doi.org/10.31032/IJBPAS/2021/10.12.5786}

\begin{abstract}
Pseudomyopia is characterized by an increased tone of the ciliary muscle and a constant accommodative effort, leading to a marked approximation of the far point. It is an apparent myopia that is acute in onset and disappears when the eye is atropinized. It is also referred to as spasm of accommodation. We report a case of an 8 year old boy, who presented with difficulty in vision for past 3 months. It was acute in onset and was initially associated with pain and headache. He had history of increased mobile usage for past 4 weeks prior to onset of symptoms. He was shown to an ophthalmologist and evaluated, diagnosed as pseudomyopia and started on cycloplegics. It had a transient improvement, but symptoms persisted. VEP was showing increased latency in both eyes. At admission he had a vision of finger counting at 2 metres in both eyes. CNS and fundus examination was normal. Repeat VEP was taken which showed increased latency bilaterally, MRI Brain was essentially normal. Diagnosis of pseudomyopia was confirmed after extensive ophthalmology evaluation. He was discharged on topical cycloplegics, symptoms improved and he is now on regular follow up.
\end{abstract}

\section{INTRODUCTION}

Pseudomyopia occurs when a spasm of ciliary muscle prevents the eye from focusing in the distance. It may be either organic or functional in origin. It can be divided into two types. The first type is the result of a functional increase in ciliary tonus, occurring intermittently and accentuated by near work $[1,2]$. The second type is the true spasm of accommodation and is considered 
pathological because of its duration and severity. The ciliary muscle is in a state of constant spasm, a difference between the refraction with and without complete cycloplegia with atropine greater than that accounted for by the normal ciliary tone [3].

\section{Case Report:}

8 year old boy, the only child of nonconsanguineous parentage with no significant past history and normal developmental milestones presented with complaints of difficulty in vision for last 4months. 4 months back child had sudden onset of headache with pain over eyes bilaterally with blurring of vision. No c/o double vision, photophobia, watering. No symptoms of other cranial nerve involvement. There was $\mathrm{h} / \mathrm{o}$ increased mobile usage for last 3 months. Child was shown in nearby hospital and given symptomatic treatment for headache. Headache and eye pain subsided but blurring of vision persisted. Shown to ophthalmologist and was diagnosed as pseudomyopia and started on cycloplegics. Visual evoked potential was done, which was showing prolonged latency bilaterally. Vision transiently improved and drug was stopped and blurring of vision persisted.

As the possibility of optic neuritis was ruled out, an ophthalmologist consultation was done. His visual acquity improved to 6/9 BE after dialation. Perimetry, anterior segment and optic disc were normal. Thus diagnosis of pseudomyopia was confirmed and child was started on topical cycloplegics. He is on regular follow up and vision has improved.

\section{DISCUSSION}

Pseudomyopia is spasm of accommodation and mostly presents in children and young adolescents.

The common symptoms are blurring of distant vision, asthenopia, headache, photophobia and diplopia. It may be either organic or functional in origin. The diagnosis of AS is clinical based on the presence of aggravating factors and shift of refraction after cycloplegia.

Apart from psychological stress and excessive near work, certain conditions predispose to it: [4-6].

- Overstimulation of parasympathetic systemocular fatigue, ocular inflammation like uveitis

- Topical miotics (parasympathomimetics and cholinergics)

- After refractive surgery: LASIK surgery and photorefractive keratectomy

- After head trauma

- Due to central lesion involving dorsal midbrain oridiopathic intracranial hypertension

- Rare causes reported are bimatoprost induced, secondary to long-standing intermittent exotropia 
- Diseases like uncontrolled Type II diabetes mellitus, myasthenia gravis.

It is a reversible condition and most important is to differentiate it from myopia and unnecessary on examination, child was alert, afebrile, vitals prescription of glasses. stable, higher mental functions- normal. Cranial nerves examination, I- normal, IIVisual acuity- B/Evision- finger counting at $2 \mathrm{~m}$, visual field, colour vision, fundus examination were normal and Swinging flash light- positive. Motor and sensory system examination was normal. No cerebellar signs or signs of meningeal irritation. Other systems examination were normal. Child was investigated.

Complete blood count, ESR and CRP were normal.

VEP showed increased P100 latency of 118 msecin right eye and $116 \mathrm{msec}$ in left eye with normalamplitude bilaterally. MRI Brain was essentiallynormal, no features of retrobulbar optic neuritis.

The possibility of retrobulbar optic neuritis, neuromyelitisoptica, refractory error and pseudomyopia were considered. An MRI Brain was taken which was essentially normal, no features of retrobulbar optic neuritis.

\section{Treatment}

- Maintain visual hygiene.

- Visual exercises to relax accommodation

- Topical cycloplegic agents

\section{CONCLUSION}

Pseudomyopia is a rising concern in today's world of increased screen time. It is the spasm of accommodation and have a good response to topical cycloplegics. It should be differentiated from myopia which can reduce the increased prescription of glasses. Screen time should be strictly restricted to age appropriate guidelines by AAP.

\section{REFERENCE}

[1] Padhy D, Rao A. Bimatoprost (0.03\%)-induced accommodative spasm and pseudomyopia. Case Reports. 2015 Nov 23; 2015: bcr2015211820.

[2] Smith JL. Accommodative spasm versus spasm of the near reflex. Journal of clinical neuroophthalmology. 1987; 7(3): 132-4.

[3] Jones RO. Physiological pseudomyopia. Optometry and vision science: official publication of the American Academy of Optometry. 1990 Aug 1; 67(8): 6106.

[4] Shetty R, Deshpande K, Kemmanu V, Kaweri L. The role of aberrometry in accommodative spasm after myopic photorefractive keratectomy. Journal of Refractive Surgery. 2015 Dec 1; 31(12): 851-3.

[5] London R, Wick B, Kirschen D. Post-traumatic pseudomyopia. 
Optometry (St. Louis, Mo.). 2003

Feb 1; 74(2): 111-20.

[6] Kawasaki A, Borruat FX. Spasm of accommodation in a patient with increased intracranial pressure and pineal cyst. Klinische Monatsblätter für Augenheilkunde. 2005 Mar; 222(03): 241-3. 